\title{
Forest Management under Fire Risk when Forest Carbon Sequestration Has Value
}

\section{StÉPHANE COUTURE AND ARNAUD REYNAUD}




\title{
Forest Management Under Fire Risk When Forest Carbon Sequestration Has Value
}

\author{
Stéphane Couture* and Arnaud Reynaud ${ }^{\dagger}$
}

November 6, 2008

\begin{abstract}
In this paper, we develop a multiple forest use model to determine the optimal harvest date for a forest stand producing both timber and carbon benefits under a risk of fire. The preferences of the representative non-industrial private forest (NIPF) owner are modeled though an expected utility specification. We introduce saving as a decision of the forest owner at any time. The problems of forest management and saving decisions are solved simultaneously using a stochastic dynamic programming method. A numerical programming method is used to characterize the optimal forest and saving policies. We apply this framework to model the behavior of a representative NIPF owner located in the Southwest of France. The empirical application indicates that a higher risk of fire will decrease the optimal rotation period, while higher carbon prices will increase the optimal harvesting age. We show that increasing the risk of fire leads to a reduction in rotation duration. On the contrary, a higher carbon price makes carbon sequestration more profitable, thereby leading to increasing the rotation duration. We then show how the carbon price/risk of fire frontier is affected by risk aversion.
\end{abstract}

Keywords: Forest Economics, Stochastic Dynamic Programming, Expected Utility, Fire risk, Carbon Sequestration

JEL Codes: C61, D81, Q23

${ }^{*}$ INRA, UMR 356 Economie Forestière. 14, rue Girardet. CS 14216. 54042 Nancy cedex. France. E-mail: couture@nancy-engref.inra.fr. fax: (33)-3-83-37-06-45, tel: (33)-3-83-39-68-60. Corresponding author.

${ }^{\dagger}$ TSE(LERNA), Université de Toulouse 1, Manufacture des Tabacs - Bât.F, 21 allée de Brienne, 31042 Toulouse. France. E-mail: areynaud@toulouse.inra.fr, fax: (33)-5-61-12-85-20, tel: (33)-5-61-12-85-12. 


\section{Introduction}

Traditionally, forests have been viewed as a source of timber used for producing goods and services. It has recently been emphasized, however, that forests also play a significant role in climate change mitigation, since carbon sequestration in forests is a major factor that affects the global carbon cycle (IPCC [1]). In the last few years, there has been an increasing tendency to consider forest ecosystems as possible sinks of carbon dioxide, recognizing forestry as carbon storage in the form of biomass. This non-timber service is produced jointly with timber, and vanishes with the standing forest stock. The decision to harvest timber therefore automatically affects the flow of stored carbon that can be got from a standing stock of forest. This joint production property is not reflected in the decision process of NIPF owners who tend to neglect the carbon service of forests, caused an external effect to society. In the absence of carbon forest markets, NIPF owners consider carbon service of forests to be external to their harvesting decisions. As a consequence, effective forest carbon sequestration may be below the social optimum. It is therefore important to determine the impact of internalizing carbon benefits into forest management decisions. The timber and carbon relationship is complicated by the uncertainty associated with the risk of fire. By significantly damaging French or European forests, the recent exceptional fire events have reminded all forest owners that fire risk is an important component of forest management (Schelhaas et al. [2]). Indeed, a forest can be partially or totally destroyed by natural calamities, resulting in the sequestered carbon being released back into the atmosphere. It follows that the regulator needs to provide incentives to mitigate the non-permanence risk and to define who should bear that risk. Such events impact the outcome of policies to sequester carbon in forest biomass. It is therefore important to understand the influence of this risk on the behavior of a NIPF owner selling carbon credits. These features raise several interesting issues: (i) what are the qualitative properties of timber supply when carbon service induces private revenue, (ii) what is the role of fire risk in this context and, finally (iii) How would the risk of release influence the amount of carbon a NIPF owner is willing to supply for a given carbon price? The purpose of this paper is to develop a model that will hopefully yield insights into these questions. First, we present a brief review of the relevant literature which provides an additional motivation for our analysis. The implications for NIPF owners of introducing carbon services have been studied in many articles, usually using a Faustmann-type framework. Several articles have considered a deterministic context (Hoen [3]; VanKooten et al. [4]; Romero et al. [5]; Diaz-Balteiro and Romero [6]; Akao [7]; Gutrich and Howarth [8]; Pohjola and Valsta [9]). More recently, the risk of fire has been introduced into such a context, (Stainback and Alavalapati [10]; Stollery [11]). These models, which are mainly a variation of the multiple use forestry modeling 
suggested by [12], add the non-timber value of forest to the well-known Faustmann model. ${ }^{1}$ In all studies assuming a deterministic context, introducing the value of carbon sequestration tends to increase optimal rotation length. On the contrary, focusing on a forest stand producing timber and carbon sequestration benefits, Stainback and Alavalapati [10] find that fire risk both decreases the land expectation value and the optimal rotation age. As a result, the amount of carbon stored in the stand decreases. In the same way, Stollery [11] adapts the modified Hartman model, allowing the fire risk to change over time as the climate warms. In their extension of the Reed model, the authors show that an increase in the risk of fire results in a downward trend in both the commercially and socially optimal forest rotation periods. When they add carbon sequestration benefits to the model, they show that the socially optimal rotation length also declines with climate warming. Our paper explores various issues associated with the harvesting behavior of an NIPF owner when carbon sequestration has value, and when there is a fire risk affecting timber production. More formally, we develop a model to characterize the optimal harvest date, the optimal quantity of sequestered carbon and the optimal timber supply for a forest stand that produces both timber and carbon benefits under risk of fire. We introduce saving as a decision of the forest-owner at any time, and we incorporate the fact the forest-owner is responsible for repayment of carbon that is released back into the atmosphere after harvesting. We extend the existing literature in several important directions. First, we analyze the impact of risk preferences on forest-owner decisions in a risky environment taking into account carbon sequestration. While forest owner risk preferences are known to be an important determinant of forest decisions, previous works have shown that risk aversion has an ambiguous impact on forest management decisions. ${ }^{2}$ Secondly, we introduce the possibility for the forest owner to diversify risk by investing in risk-free assets. As a result, forest management decisions are intrinsically linked with saving decisions. Thirdly, in complement to the existing literature based on the Faustmann framework, we characterize the optimal harvesting decisions under fire risk and the risk aversion of the forest owner using a stopping method in a stochastic dynamic programming framework. Fourthly, we develop a numerical programming method to char-

\footnotetext{
${ }^{1}$ More generally, privately optimal rotation age has been studied extensively in the Faustmann model, where the forest owner maximizes the net present value of harvest revenue (Samuelson [13]). It may be the case, however, that private landowners are interested not only in the present value of net harvesting revenue, but also in the amenity services provided by forest stands. Analyzing how the amenity valuation affects the privately optimal rotation has been investigated by Hartman [12], Strang [14], and later Johansson and Löfgren [15], as well as Bowes and Krutilla [16], Koskela and Ollikainen [17], in a deterministic context, and more recently Englin it et al. [18], and Amacher et al. [19] in a risky context. Unlike other amenity benefits such as recreational use, when carbon benefits are internalized, a landowner must pay for carbon emissions emitted due to tree mortality. There is thus an additional cost associated with catastrophic mortality

${ }^{2}$ See, for instance Caulfied [20] who uses dominance stochastic analysis or Taylor and Fortson [21], Valsta [22], Gong and Löfgren [23] who have adopted a mean-variance approach. Alvarez and Koskela [24] use a Wicksellian single rotation problem to show the impact of landowner risk aversion on the expected length of the rotation period. They show that, under risk aversion, higher forest value volatility decreases the optimal harvesting threshold.
} 
acterize optimal management policies over a grid of parameters. We have applied this framework to model the behavior of a representative NIPF owner located in the south-west France. Finally, we develop the sensitivity analysis of harvesting in terms of risk, risk aversion and carbon price. Numerical illustrations indicate that higher risk will decrease the optimal rotation period, while higher carbon prices will increase the optimal harvesting age. Our findings indicate that increased relative risk aversion accelerates the optimal length of the rotation period. Finally, the frontier of carbon price/risk space to maintain the same rotation age is shown to be affected by risk aversion.

The rest of the paper is organized as follows. In Section 2, we describe the forest management model and we present the stochastic dynamic programming (SDP) method we used. Section 3 deals with an empirical application to the case of a French representative NIPF owner. We conclude by a brief summary of our findings.

\section{The model}

In this section, we present the main characteristics of the multiple forest-use dynamic model under fire risk and carbon sequestration benefits.

\section{$2.1 \quad$ Specification of the model}

\section{Characteristics of the NIPF owner}

We consider a NIPF owner managing an homogeneous, even-aged forest stand. ${ }^{3}$ We denote by $A$ the area of forest (in hectares). The problem of the forest owner is to determine the optimal sequence of harvest ages. Forest owner preferences are represented by a utility function denoted by $U(c)$ with $U^{\prime} \geq 0, U^{\prime \prime} \leq 0$ and where $c$ represents the consumption of the forest owner.

\section{Fire risk}

Following the existing literature on forest management under fire risk (see Reed [25] among others), we assume that the risk of fire can be described by a Poisson process. This assumption implies that the risk of fire is the same every year. Over a short interval $d t$ of time, the probability of a fire is $\lambda d t$, where $\lambda$ is the mean arrival rate, with probability $(1-\lambda d t)$ that there is no fire. We assume that if a fire occurs, no salvage is possible. If a fire occurs, then the forest owner is assumed to replant the forest stand with a planting cost $\mu$ per unit of surface.

\footnotetext{
${ }^{3}$ In several countries, non-industrial timber production represents a significant share of total timber supply (roughly $60 \%$ in most Scandinavian countries and the US). In France, NIPF owners constitute the main type of forest ownership, representing roughly $75 \%$ of forest areas.
} 


\section{Timber benefits}

We denote by $v(t)$ the volume of wood per unit of surface at age $t$. This volume is assumed to increase with time according to a growth function $g(t)$. We assume that the growth process of a tree is finite, that is: $\lim _{t \rightarrow \infty} g^{\prime}(t)=0$

We consider a multiple forest-use model. The harvested timber volume is used to produce several forest products such as sawtimber, pulpwood, fuelwood, etc. These forest products are indexed by $k$ with $k=1, \ldots, K$ and we denote by $p_{k}$ the net price associated with product $k$. We assume that the share of timber products varies according to tree age. ${ }^{4}$ We denote by $\delta_{k}(t)$ the share of timber volume used for product $k$ for a tree of age $t$. By definition, we have:

$$
\sum_{k=1}^{K} \delta_{k}(t)=1 \quad \forall t
$$

It follows that, by choosing a harvesting date, the forest owner chooses not only the volume of timber to be harvested, but also the breakdown of this volume between all possible forest products. Assuming that the forest is replanted after being harvested, the revenue per unit of surface (net of replanting cost) from harvesting a forest stand at age $\bar{t}$ is given by:

$$
\sum_{k=1}^{K} p_{k} \cdot \delta_{k}(\bar{t}) \cdot v(\bar{t})-\mu
$$

\section{Carbon benefits}

The forest stand generates carbon sequestration which is valued by society. Society therefore pays a revenue for the carbon sequestered by the forest stand. We assume that, at date $t$, the forest owner receives a payment corresponding to the value of the incremental increase in carbon sequestration. Let us denote by $p_{c}$ the price per metric ton of carbon. Then the payment at date $t$ per unit of surface for carbon sequestration received by the forest owner is written:

$$
p_{c} \cdot \alpha \cdot v^{\prime}(t)
$$

where $\alpha$ denotes the conversion factor to convert a wood volume into metric tons of carbon, and $v^{\prime}(t)$ is the derivative of $v(t)$ with respect to $t$.

The decay of forest products produces carbon emissions. Carbon emissions are modeled as a

\footnotetext{
${ }^{4}$ For instance, for young trees the share of the timber volume that can be used for sawtimber is generally low, with most of the timber volume serving as pulpwood in that case. As trees grow and become older, the share of timber volume used for sawtimber increases. We assume that this share is given to the forest owner, but it varies with the age of trees.
} 
linear process where an equal amount decays at each instant until the whole carbon pool is released back into the atmosphere. However, forest products differ according to their lifespan. We denote by $T_{k}$ the lifespan (in years) of forest product $k$. If the forest owner harvests a forest plot of age $\bar{t}$ at date $t$, then the instantaneous flows of carbon per unit of area due to product $k$ will be :

$$
\frac{\alpha \cdot \delta_{k}(\bar{t}) \cdot v(\bar{t})}{T_{k}}
$$

over the period $\left[t, t+T_{k}\right]$. We assume that carbon emissions due to forest product decay give rise to payment by the forest owner at the harvesting date. This payment corresponds to the discounted value of future carbon releases from all forest products at date $t$. Denoting by $r$ the rate of pure present preference of the NIPF owner, this discounted value for product $k$ is written:

$$
\int_{t}^{t+T_{k}} p_{c} \cdot \frac{\alpha \cdot \delta_{k}(\bar{t}) \cdot v(\bar{t})}{T_{k}} \cdot \exp ^{-r(\tau-t)} d \tau=\Phi_{k} \cdot \delta_{k}(\bar{t}) \cdot v(\bar{t})
$$

where:

$$
\Phi_{k}=p_{c} \cdot \frac{\alpha}{T_{k}} \cdot \frac{1-\exp ^{-r T_{k}}}{r}
$$

where $\Phi_{k}$ can be interpreted as an implicit unit carbon tax for product $k$ paid by the forest owner.

\section{Forest owner wealth}

Forest owners derive their utility from consumption. At each date, the forest owner therefore chooses the amount of wealth used for consumption, the remainder being invested in a financial asset with a risk free rate of return denoted by $\eta$. For simplicity, we assume that no loans are possible, that is $w(t)>0$ where $w(t)$ represents the forest owner wealth invests in risk-free saving. In such a context, timber production for a NIPF owner can be viewed as a risky asset that must be managed to secure consumption over the long-run. The problem of the forest owner consists in optimizing a portfolio comprising a risky asset (forest) and a risk-free asset (saving) in order to maximize the expected utility of consumption over time. Hence, the consumption-savings tradeoff will have an impact on forest management, and vice-versa. ${ }^{5}$

Without risk occurrence, the dynamic of wealth depends upon whether the forest stand is harvested or not. If the forest owner does not harvest the stand then the wealth is increased by the interests from saving $\eta \cdot w(t)$, and by the payment corresponding to the increase in carbon

\footnotetext{
${ }^{5}$ There are only a few studies dealing with the consumption-savings tradeoff in the context of forest management (Tahvonen [26] ; Tahvonen and Salo[27] ; Salo and Tahvonen [28] ; Tahvonen [29] ; Uusivuori and Kuuluvainen [30] ; Couture and Reynaud [31]). These forest rotation models consider this tradeoff within a maximizing utility framework and a purely deterministic context except Couture and Reynaud [31] but none of these studies incorporate carbon benefits.
} 
sequestration, $A \cdot p_{c} \cdot \alpha \cdot v^{\prime}(t)$, but is reduced by the level of consumption, $c(t)$. If the forest owner harvests the stand, then his/her wealth increases from timber benefits $A \cdot\left[\sum_{k} p_{k} \cdot \delta_{k}(\bar{t}) \cdot v(\bar{t})\right]$ and from savings $\eta \cdot w(t)$ but decreases due to the carbon cost of product decay, $A \cdot\left[\sum_{k} \Phi_{k} \cdot \delta_{k}(\bar{t}) \cdot v(\bar{t})\right]$, the replanting $\operatorname{cost} A \cdot \mu$ and the level of consumption, $c(t)$.

If a fire occurs, all the timber production is lost. We assume that the forest owner does not pay for the carbon emissions. ${ }^{6}$ In that case, wealth increases from savings $\eta \cdot w(t)$ but decreases due to the replanting cost $A \cdot \mu$ and to the level of consumption, $c(t)$.

\subsection{The optimality conditions}

The forest owner's problem is to choose the flow of consumption $c(t)$ over time and the harvesting date $\bar{t}$ so as to maximize his/her discounted expected utility. In other words, the dynamic optimization problem at each period consists in determining if the forest stand must be harvested or not, and if the revenue flow must be used for consumption or saving. Since the problem is dynamic and stochastic, the optimal decision path depends on forest owner risk preferences. Risk preferences refer to the forest owner's desire to smooth consumption across states of nature.

Applying the basic stochastic dynamic programming technique of optimal stopping (Dixit and Pindyck [32]), the Bellman equation is defined as follows:

At $t<\bar{t}^{*}(w)$,

$$
\begin{gathered}
J(t, w)=\max _{\{c\}} U(c) d t+e^{-r t}\left[(1-\lambda d t) J\left(t+d t, w+(\eta w-c) d t+p_{c} \alpha A v^{\prime}\right)\right. \\
+\lambda d t J(0, w+(\eta w-c) d t-A \mu)]
\end{gathered}
$$

where $J(t, w)$ is the expected current value of future utilities to be optimized by the forest owner, $t$ is the age of the forest stand in years, and $\bar{t}^{*}$ represents the optimal age of harvest depending on wealth $w$. Notice that since the forest stand grows according to growth function $g(t)$, it is strictly equivalent to define the value function as $J(t, w)$ or as $J(v, w)$. In the application, we will use this property, and we may alternatively consider the optimal harvesting date or the optimal timber volume at the harvesting date.

The right-hand side of the Bellman equation is made up of two terms: the instantaneous utility which only depends upon present consumption, and the continuation value which is stochastic. Without risk occurrence, the wealth of the forest owner during time interval $\Delta_{t}$ is increased by savings and carbon benefits obtained for the considered period, and decreases due to consumption.

\footnotetext{
${ }^{6}$ Empirical evidence suggests that in case of fire, public authorities are very reluctant to impose carbon release payments on forest owners.
} 
If a risk occurs, then forest owner wealth increases due to savings returns but decreases due to consumption and planting costs.

The optimal harvesting age, $\bar{t}^{*}$, is first determined by a value matching condition:

$$
J\left(\bar{t}^{*}, w\right)=J\left(0, w+A \cdot\left[\sum_{k}\left(p_{k}-\Phi_{k}\right) \cdot \delta_{k}\left(\bar{t}^{*}\right) \cdot v\left(\bar{t}^{*}\right)\right]-A \mu\right)
$$

which means that at the optimal date, the forest owner must be indifferent as to cutting the forest stand or not. In other words, at the optimal harvesting age, the payoff received by the forest owner exactly compensates for exercise of the harvesting option.

However, under uncertainty, the value matching condition is not sufficient to find the optimal stopping time, since it yields an infinite number of solutions. An additional smooth pasting condition must typically be specified. This condition requires the derivatives of both sides of the value matching condition to be equated. The smooth-pasting condition must be written:

$$
\begin{gathered}
J_{t}\left(\bar{t}^{*}, w\right)=J_{w}\left(0, w+A \cdot\left[\sum_{k}\left(p_{k}-\Phi_{k}\right) \cdot \delta_{k}\left(\bar{t}^{*}\right) \cdot v\left(\bar{t}^{*}\right)\right]-A \mu\right) \\
{\left[A v^{\prime}\left[\sum_{k}\left(p_{k}-\Phi_{k}\right) \cdot \delta_{k}\left(\bar{t}^{*}\right)\right]\right] \forall w .}
\end{gathered}
$$

This condition requires the derivatives of the value function to match at optimal date $\bar{t}^{*}$.

The optimal harvest date and optimal consumption-savings path are defined by the three conditions (7), (8), and (9).

\section{Application to maritime pine forests in southwest France}

\subsection{Specification of the empirical model}

We apply this modeling to represent the behavior of a representative NIPF owner located in SouthWest France (Aquitaine region). The Aquitaine forest covers a total of 1.8 million hectares. It is the largest forest area of the EU. NIPF owners represent $92 \%$ of the total area. This natural forest has a dominating economic role. The main objective of Aquitaine forests is to produce wood. Aquitaine represents $20 \%$ of the French wood sector. The main tree species is maritime pine ( $70 \%$ of the total area). In this region, forest fires are one of the main problems for forests. These fires threaten the different functions of the forest: economic, social, and ecological. The protection policy of the Aquitaine forest against fire risks developed over several years is exemplary. Policy measures combining prevention and fines have resulted in very efficient control. Since 1985, the average size 
of burnt surface areas has diminished.

\section{The characteristics of the NIPF owner}

The average size of the observed private forest estates in Aquitaine is equal to 12 hectares $(A=12)$. Preferences of the forest owners are described by a strictly increasing and concave Von-Neumann Morgenstern utility function. As suggested by Eeckhoudt and Gollier [33], we specify a Constant Relative Risk Aversion utility function: $U(c)=\frac{c^{1-\beta}}{1-\beta}$ with $\beta$ being the Arrow-Pratt coefficient of absolute risk aversion. Initially we fix $\beta$ at $0.5 .^{7}$ This level corresponds to a moderately risk-averse forest owner. The rate of pure present preference for the NIPF owner, $r$, is equal to 0.03. The no-risk rate $\eta$ of the financial asset is also equal to 0.03 .

\section{Fire risk}

The risk of fire is described as a Poisson process. In undisturbed temperate forests, the average rate of disturbance is between $0.5 \%$ and $2 \%$ per year, and this rate seems to hold over a number of different ecosystems (Stainback and Alavalapati [10]). In Aquitaine, fires have burned on average 3,200 hectares per year over the period 1981 to 2003 . This area represents roughly $0.17 \%$ of Aquitaine's forest land base $(1,890,481$ hectares). It follows that the Poisson parameter for the risk of fire in Aquitaine is estimated to be $\lambda=0.17 \%$.

\section{Timber benefits}

The estimate of the growth function parameters for the maritime pine in Aquitaine has been obtained using a nonlinear regression based on a data set derived from Vanniere [34]. Based on the existing literature (Koskela and Ollikainen [35]), we have assumed that the growth process could be approximated by a logistic function. The resulting estimated function is:

$$
g(t)=\frac{424}{1+40.6914 e^{-0.1221 t}}
$$

where $t$ is the age of the stand (the number of observations is 11 ; and the $R^{2}$ coefficient is equal to 0.9977$)$. Some statistics on the timber volume per ha as a function of tree age can be found in Table 1.

We assume that the volume of wood in the forest stand can produce two outputs $(K=2)$, namely sawtimber and pulpwood. Wood products are indexed by $k=\{s, p\}$ respectively for sawtimber and pulpwood. As discussed previously and following (Bateman and Lovett[36]), information regarding

\footnotetext{
${ }^{7}$ There is currently no available estimate for this parameter in the case of a NIPF owner facing a climate risk. More generally, there is neither no consensus on the level of the coefficient of risk aversion for economic agents. Static comparative exercises with respect to the level of the risk aversion will be conducted.
} 
the proportion of wood allocated to each end use is required (Bateman and Lovett[36]) to incorporate carbon release into the carbon-timber forest management model. We assume that these proportions vary according to time. This variation reflects the fact that in the case of young trees, timber is only used for pulpwood. Then as the trees grow, the proportion of sawtimber increases with time. Using data for French timber production in 1999-2003, and a logistic equation, the proportion of sawtimber $\delta_{s}(t)$ as a function of tree age $t$ is written:

$$
\delta_{s}(t)=\frac{0.8028}{1+2748.8 e^{-0.2636 t}}
$$

The $R^{2}$ coefficient is equal to 0.9979 . By definition, the proportion of pulpwood $\delta_{p}(t)$ as a function of tree age $t$ is written:

$$
\delta_{p}(t)=1-\delta_{s}(t)
$$

Sawtimber and pulpwood prices are assumed to be constant and set at the following values: $p_{s}=24.2$ euros per cubic meter and $p_{p}=7.5$ euros per cubic meter (data from "Forêts de France"). In Table 1, we have computed the value of forest product sales according to the age of the trees. For young tree generations, the gross value of forest sales is very low, since most of the timber volume is used for pulpwood. As the trees grow, then the share of the timber volume that can be used for sawtimber increases. Then the gross value of forest sales increases. Finally, the planting cost, $D$, is equal to 1000 euros per hectare (Guo [37]).

\section{Carbon benefits}

The amount of carbon sequestered in a standing forest comes directly from the forest's biomass. ${ }^{8}$ As suggested by Stavins [38], carbon sequestration occurs in four components of the forest: trees, understory vegetation, forest floor, and soil. However, woody parts generally make up around $80 \%$ of a forest's total biomass. ${ }^{9}$

As discussed previously, the payment at date $t$ per unit of surface for carbon sequestration received by the forest owner is $p_{c} \cdot \alpha \cdot v^{\prime}(t)$ where $\alpha$ denotes the conversion factor to convert a wood volume into metric tons of carbon. Following Stainback and Alavalapati [10], the conversion coefficient is 0.3 metric tons of carbon per cubic meter. Incorporating net carbon sequestration implies choosing a price $\left(p_{c}\right)$ for sequestered carbon. Previous studies have used a variety of methods to calculate this price. Some authors, for instance, have used econometric approaches based on observations of landowners' actual behavior confronted with the opportunity costs of alternative

\footnotetext{
${ }^{8}$ Forest biomass consists primarily of above-ground and below-ground tree components (stems, branches, leaves, and roots); other woody vegetation; and mosses, lichens and herbs.

${ }^{9}$ The share varies however greatly among forest types.
} 
Table 1: Dynamics of forest products, sales and carbon benefit

\begin{tabular}{lccccc}
\hline Age & $\begin{array}{c}\text { Timber volume } \\
\text { year }\end{array}$ & $\begin{array}{c}\text { Share of sawtimber } \\
\text { m3/ha }\end{array}$ & $\begin{array}{c}\text { Timber sales }^{a} \\
\text { Incremental } \\
\text { timber sales }^{b} \\
\text { euros } / h a\end{array}$ & $\begin{array}{c}\text { Incremental } \\
\text { carbon benefits }^{c} \\
\text { euros } / h a\end{array}$ \\
\hline 5 & 18 & 1.2 & 5 & - & - \\
10 & 33 & 1.6 & 11 & 6 & 43 \\
15 & 56 & 2.7 & 29 & 18 & 71 \\
20 & 93 & 5.8 & 97 & 68 & 111 \\
25 & 145 & 15.6 & 390 & 293 & 155 \\
30 & 207 & 39.3 & 1,378 & 988 & 187 \\
35 & 271 & 64.1 & 2,917 & 1,540 & 189 \\
40 & 324 & 75.0 & 4,083 & 1,166 & 161 \\
45 & 363 & 78.4 & 4,782 & 699 & 117 \\
50 & 389 & 79.5 & 5,191 & 409 & 76 \\
55 & 404 & 80.0 & 5,426 & 235 & 46 \\
60 & 413 & 80.2 & 5,558 & 133 & 27 \\
65 & 418 & 80.2 & 5,632 & 74 & 8 \\
70 & 421 & 80.3 & 5,673 & 41 & 15 \\
\hline
\end{tabular}

$a^{a}$ : Gross value of timber products, $p_{s} \cdot \delta_{s}(t) \cdot v(t)+p_{p} \cdot \delta_{p}(t) \cdot v(t)$.

${ }^{b}$ : Gross value of incremental timber products over the last 5 years.

${ }^{c}$ : Market value of carbon sequestered over the last 5 years, $p_{c} \cdot \alpha \cdot(v(t)-v(t-5))$.

land uses (Stavins [38]; Newell and Stavins[39]). For a survey of the literature, see Sedjo et al. [40], and more recently Richards and Stokes [41]. The value of carbon varies in the literature and usually ranges from $\$ 0$ to $\$ 200$ per metric ton (Stainback and Alavalapati [10]). Like Pohjola and Valsta [9], we initially fix $p_{c}$ to 10 euros per ton and we will conduct some sensitivity analysis on this parameter.

Sawtimber is modeled to decay over $T_{s}$ years, and pulpwood over $T_{p}$ years. As suggested by Stainback and Alavalapati [10], the decay of sawtimber and pulpwood is modeled to be a linear process ${ }^{10}$ in which an equal amount decays each year until all of the carbon pool has been released back into the atmosphere. Following Stainback and Alavalapati [10] and Vallet [42], we fix $T_{s}=60$ years and $T_{p}=5$ years.

The last column in Table 1 gives the incremental gross carbon benefits computed over the last 5 years. As it can be seen, the value of gross carbon benefits is maximized for a harvesting date around 35 years. One should, however, keep in mind that these values do not take into account the cost of forest-product carbon decay paid at the harvesting date.

\footnotetext{
${ }^{10}$ Stollery [11] assumes that at harvest, a proportion of the sequestered carbon is quickly transferred back to the atmosphere, and the remainder of the carbon goes into long-term product storage that decomposes at a exogenous and constant rate.
} 


\subsection{Solving the stochastic dynamic programming problem}

\subsubsection{Method}

The method for solving the stochastic dynamic programming problem used here is based on the approach developed by Howitt et al. [43] and is briefly presented here. The methodology comprises two stages. First, based on a value iteration approach, we numerically identify the value function, the solution to the problem. Second, the optimal decision rule is obtained by an algorithm based on the recurrence relation of the stochastic dynamic programming using the first stage value function approximation.

In the first stage, we need to estimate the value function $J($.$) defined by the three equations$ (7), (8), and (9). Since no analytical solution of this equation can be found, a numerical procedure was used. We use a value iteration approach, meaning that we seek a numerical approximation $\widehat{J}($.$) to the infinite horizon value function that maximizes the value of the problem resulting from$ decisions made in the future. The main steps of the value iteration algorithm are presented in Judd [44]. It consists of assigning an initial value for the value function, and then recursively solving the maximization problem until the implied carry-over value function converges to an invariant approximation. The interested reader may also refer to Howitt et al. [43] for an implementation of the value iteration algorithm with a recursive utility and to Couture and Reynaud [31] for an extension of this approach to a multi-dimensional case.

In order to solve the Bellman's equation, a specific functional form for $\widehat{J}($.$) must be chosen to$ approximate the solution to the infinite-horizon problem. Howitt et al. [43] have used a Chebychev Polynomial form, for instance, whereas Couture and Reynaud [31] used a second-order polynomial approximation because they had a lot of state variables. Here we specify a second-order Chebychev Polynomial form which has good interpolation properties, see (Judd [44]).

\subsubsection{Convergence}

The value function iteration program was written in GAMS. The quasi-stabilization of the value function was achieved after 100 iterations. Moreover, the residuals of the Bellman's equation at each discretized point were small enough to consider that the Chebychev polynomial form is a good approximation of the unknown value function.

\subsubsection{The estimated value function}

In Figure 1, we have plotted the estimated value functions for three levels of $t$ (or equivalently for three levels of timber volume). These value functions possess good concavity properties since they 
Figure 1: The estimated value function $J(., w)$ as a function of wealth

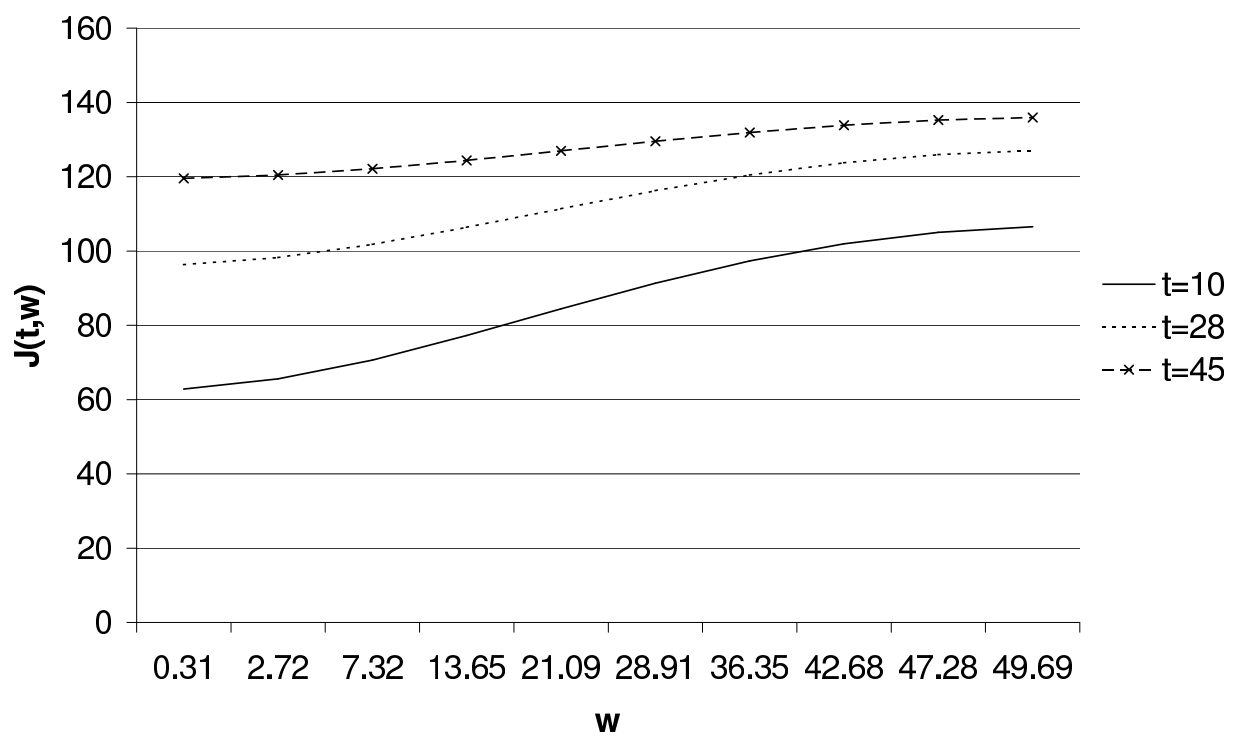

are increasing and concave with respect to $w$ that is with respect to forest owner wealth. First, the fact that $J(., w)$ increases with $w$ for a given $t$ means that the forest has a low value if $w$ is low and a high value in $w$ is high. The intuition of this result is that if the wealth is low, then the consumption is highly dependent upon forest revenue. A low value for the forest make it easier to harvest the stand. Second, the differences between the three value functions plotted on Figure 1 decrease as the $w$ increases. For a high level of savings, consumption is highly secured.

Next, in Figure 2, we have plotted the estimated value function for three levels of savings as a function of $t$. The value function also has good concavity properties. For a high level of $t$, that is in the case of a high volume of timber, the value function does not seem to be strongly affected by the level of savings. Hence, the three curves seem to converge as $t$ increases.

\subsection{Simulation results}

The main objective of this section is to analyze the change in forest management when carbon sequestration is additionally considered. In order to study this effect, we first analyze the case without a carbon price (benchmark case). 
Figure 2: The estimated value function $J(t,$.$) as a function of time$

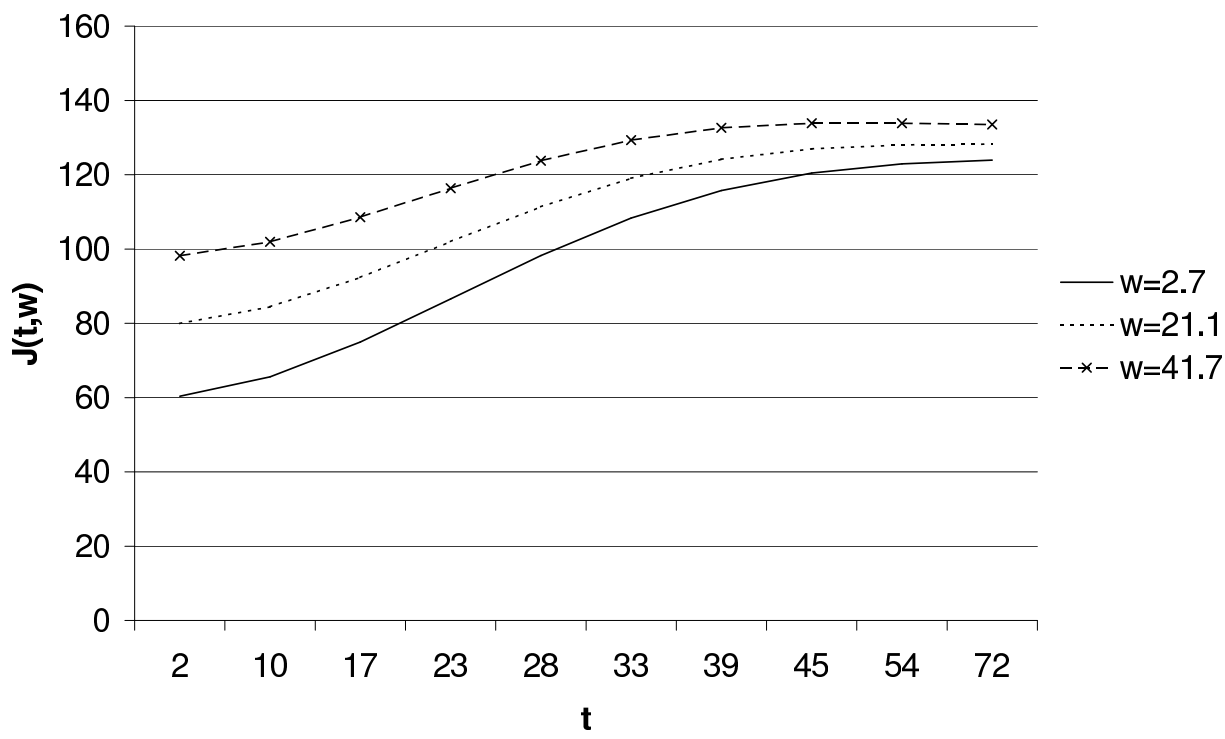

\subsubsection{Simulating the model without carbon prices}

We consider the forest owner stochastic dynamic optimization problem without any carbon payments. This situation will be referred to as the benchmark case. The model has been simulated over a very long time horizon (200 periods). Those simulations allow us to focus first on the optimal forest management decisions and second, on the optimal consumption-savings strategies of the risk averse forest owner.

\section{Optimal forest decisions}

Figure 3 presents the dynamics of the timber stock. As shown in Figure 3, in the two-use model, the optimal rotation time is 38 years. Every 38 years, the forest owner harvests his forest stand. At this optimal date, the optimal total volume of timber is $304.36 \mathrm{~m}^{3} / \mathrm{ha} .72 \%$ of this volume is used for sawtimber and $28 \%$ for pulpwood.

\section{Carbon sequestration}

We now analyze the dynamics of the carbon stored in the timber stand and forest products over time, see Figure 4. 
Figure 3: Dynamics of timber volume

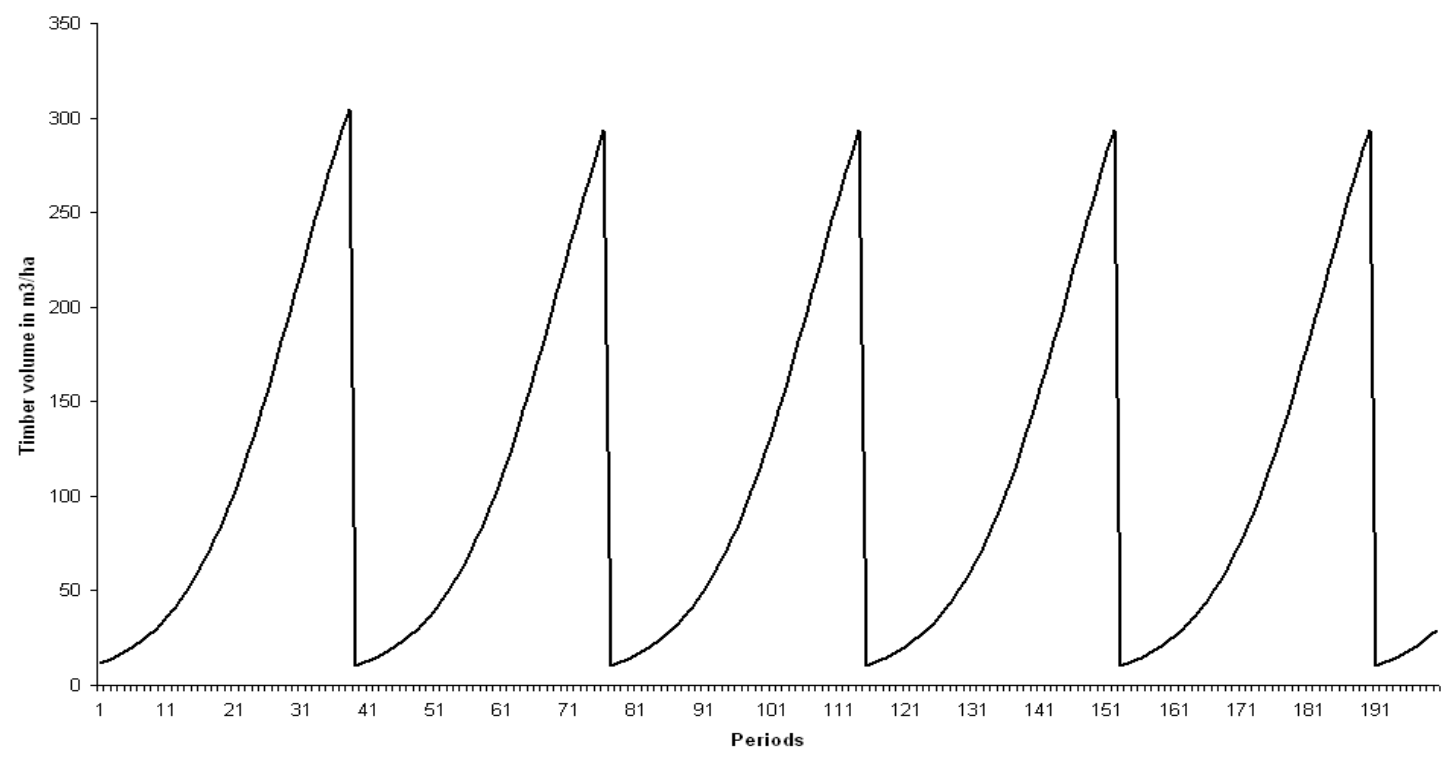

First, we focus on the dynamics of the carbon stored in the timber stand. As expected, the carbon stored in the timber stand follows a pattern similar to the wood dynamics. At the optimal harvesting date, the quantity of carbon sequestered in the forest stand is equal to 102.48 tons/hectare, compared to the maximum absorption rate of maritime pine equal to 127.2 tons/hectare.

Second, we consider the dynamics of the global carbon sequestered (both in the forest stand and in forest products). From year 1 to year 38, the increase in global carbon sequestration only results from the forest growth process. Both the global carbon sequestration curve and the timber stand carbon sequestration curve coincide exactly. The first harvest occurs at date 38, when the timber carbon sequestration level is equal to $91.31 \mathrm{t} / \mathrm{ha}$. Since $72 \%$ of the timber is used for sawtimber at this harvest date, $65.8 \mathrm{t} / \mathrm{ha}$ of carbon are transferred to sawtimber, the remainder being stored in pulpwood. Then, the carbon stored in products starts to be released at an annual rate of 1.10 ton/ha for sawtimber and 5.11 ton/ha per year for pulpwood. In the same way, since the forest is replanted immediately after being harvested, living trees start to store carbon again. The global carbon sequestration decreases up to the date when the marginal increase in carbon stored in the forest stand becomes greater than the marginal release in carbon from sawtimber and pulpwood. From this date, the global level of stored carbon increases up to the next rotation age.

Third, the curve of carbon stored in sawtimber presents an inflexion point (after the second harvest). This is due to the fact that the optimal rotation age (38 years) is shorter than the lifespan of sawtimber (60 years).

Finally, the global carbon sequestration path converges cyclically toward a value equal to 88 
t/ha.

Figure 4: Dynamics of carbon stored in the timber stand and products

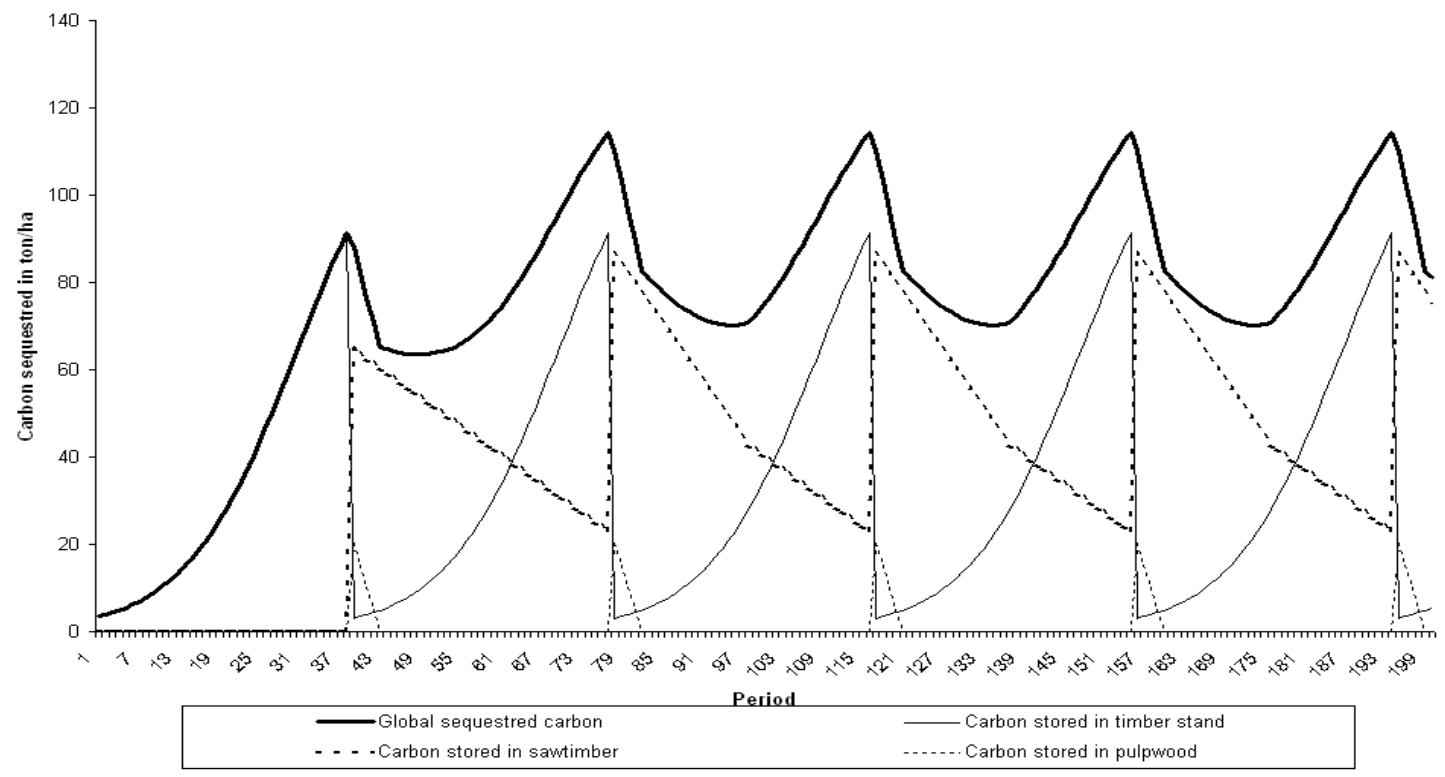

\section{The optimal consumption-savings decisions}

We focus here on the optimal consumption-savings strategies of the risk averse forest owner. Figure 5 presents the dynamics of consumption and wealth over time.

The dynamic path of wealth appears to be cyclical. First, the wealth of the forest owner decreases up to the optimal harvesting date, when it increases due to the revenue from timber sale. Then the wealth starts to decrease again. This process is repeated cyclically. The fact that the saving level is null at the harvesting dates (38 years, 76 years,...) is not surprising, given the discussion on the value function following Figure 2. Harvesting dates correspond to dates at which the forest stock is high. But as already discussed, for a high level of timber, the value function is not affected by the level of savings. Hence it is optimal to reduce savings as the forest stock grows.

The expected wealth takes into account the probability of forest stand loss due to fire. Since the optimal level of consumption depends on this expected value, it is interesting to analyze how the expected wealth of the forest owner evolves over time.

Both forest and saving stocks are managed by the forest owner in order to stabilize consumption over time. This objective is correctly achieved since, as shown in Figure 5, fluctuations in consumption are relatively small compared to wealth fluctuations, for instance. Notice that the forest owner determines the level of consumption at each date on the basis of the expected wealth composed of savings and the expected value of the timber volume at this period. Hence, the consumption flow 
Figure 5: Dynamics of consumption-wealth-expected wealth

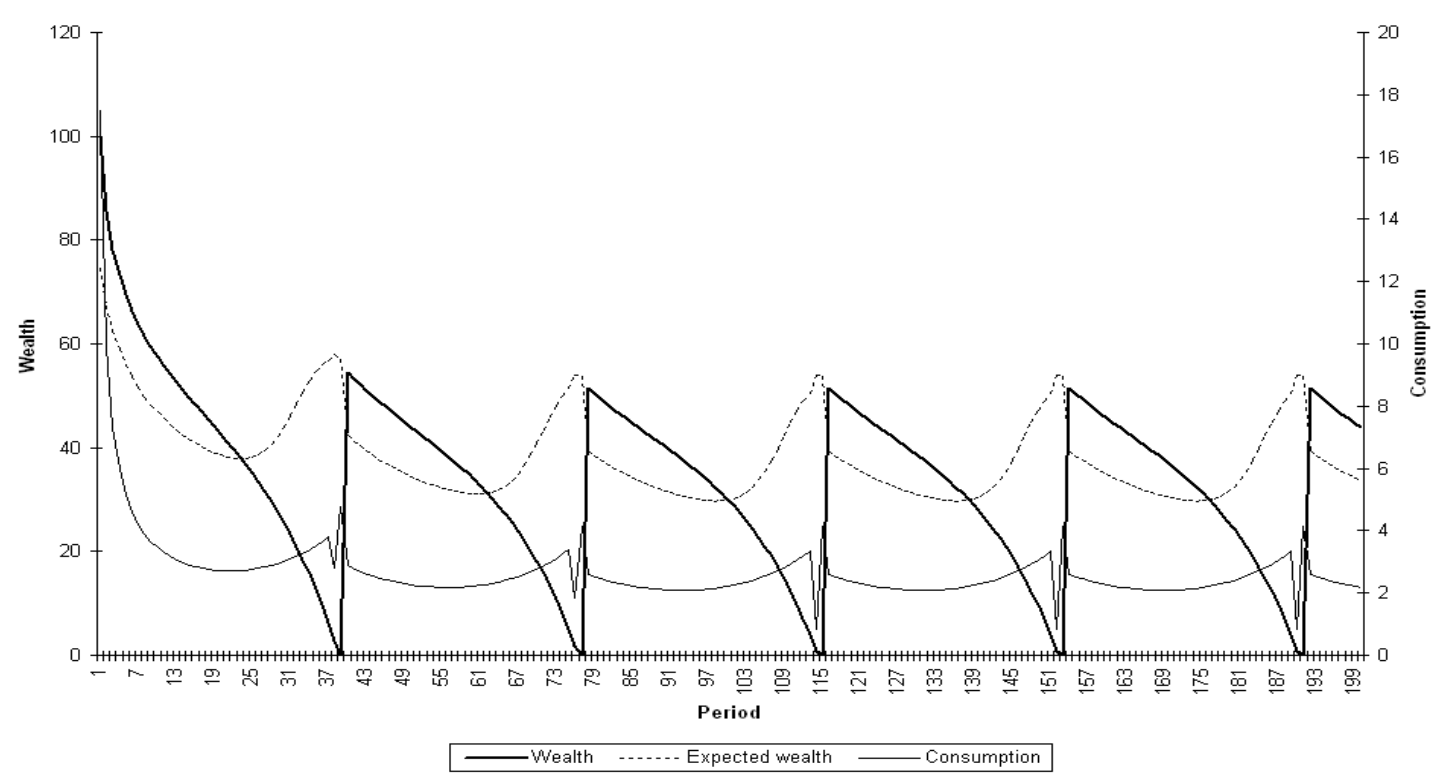

decreases as the expected wealth decreases, and increases in the opposite case.

\subsubsection{Introducing a price for carbon sequestration}

We now explore the model incorporating a carbon price equal to 10 euros per ton of sequestered carbon.

When such a carbon price is implemented, forest owners face a more complex optimization problem. They must determine the optimal rotation length, not only with respect to the profit gained from selling wood products (namely sawtimber and pulpwood), but also taking into account the net payoffs generated by carbon sequestration. Obtaining revenues from carbon sequestration during the growing phase of the forest leads to an increase in its value. Hence, delaying the date of harvesting is favorable, not only because more wood volume can be sold, but also because more gains can be obtained from carbon sequestration. Moreover, postponing the harvest date also means that carbon taxes, which reflect the carbon release at harvest time, must be paid later (in other words, due to discounting, there is a difference in the discounted value of carbon payments). Carbon prices generate a net positive benefit for the forest owner for this reason. This benefit is balanced, however, by the increase in fire risk exposure when the forest owner chooses to delay the harvesting date.

In the next paragraphs, we examine the effect of carbon price, forest size, fire risk and risk preferences of the forest owner on the optimal rotation duration. 


\section{Impact of carbon price}

Table 2 presents the optimal rotation duration for several carbon prices. As expected, introducing a carbon price extends the optimal rotation period, compared to the case without a carbon value. This effect is stronger with a high carbon price. For example, for $p_{c}=10$ euro/ton, the optimal rotation duration is 42 years, compared to 38 years in the benchmark case without carbon value. With a carbon price equal to $p_{c}=80$ euro/ton, the length of optimal rotation exceeds 50 years. Doubling the price of carbon increases the rotation length almost linearly, with an average increase of 3.5 years. The changes in optimal rotation length increase the carbon storage during the rotation period, by 12 tons/ha with a carbon price of 10 euro/ha up to 29 tons/ha with a carbon price of 100 euro/ha. The increases in stand volume are between $38 \mathrm{~m}^{3} / \mathrm{ha}$ and $95 \mathrm{~m}^{3} / \mathrm{ha}$. Carbon prices induce longer rotations, thereby increasing the amount of carbon stored on the stand. The amount of carbon sequestered is greater for higher carbon prices.

Table 2: Optimal rotation length, and timber volume and carbon storage as a function of carbon price

\begin{tabular}{lllllll}
\hline & \multicolumn{6}{c}{$\left.\begin{array}{c}\text { Carbon price } \\
(\text { euro/t }\end{array} \mathrm{CO}_{2}\right)$} \\
& 0 & 10 & 20 & 40 & 80 & 100 \\
\hline $\begin{array}{l}\text { Rotation length } \\
(\text { years })\end{array}$ & 38 & 42 & 45 & 49 & 52 & 53 \\
$\begin{array}{l}\text { Timber volume } \\
\left(\mathrm{m}^{3} / \mathrm{ha}\right)\end{array}$ & 304 & 342 & 363 & 385 & 396 & 399 \\
$\begin{array}{l}\text { Carbon storage } \\
(\text { ton } / \mathrm{ha})\end{array}$ & 91 & 103 & 109 & 116 & 119 & 120 \\
\hline
\end{tabular}

With carbon prices, the proportion of sawtimber increases considerably due to longer rotation periods, whereas the proportion of pulpwood decreases because it has a shorter life span than sawtimber (Table 3).

Table 3: Timber volume as a function of carbon price

\begin{tabular}{|c|c|c|c|c|c|c|}
\hline & \multicolumn{6}{|c|}{$\begin{array}{l}\text { Carbon price } \\
\left(\text { euro } / t \mathrm{CO}_{2}\right)\end{array}$} \\
\hline & 0 & 10 & 20 & 40 & 80 & 100 \\
\hline \multicolumn{7}{|c|}{ Timber volume $\left(m^{3} / h a\right)$} \\
\hline Sawtimber & 218 & 263 & 286 & 307 & 317 & 320 \\
\hline Pulpwood & 86 & 79 & 77 & 78 & 79 & 79 \\
\hline Total & 304 & 342 & 363 & 385 & 396 & 399 \\
\hline \multicolumn{7}{|c|}{ Change relative to the benchmark case (no value for carbon) (\% } \\
\hline Sawtimber & & 20.6 & 31.2 & 40.8 & 45.4 & 46.8 \\
\hline Pulpwood & & -8.1 & -10.5 & -9.3 & -8.1 & -8.1 \\
\hline Total & & 12.5 & 19.4 & 26.6 & 30.3 & 31.2 \\
\hline
\end{tabular}


Table 4: Net revenues from timber production, carbon sequestration as a function of carbon price Carbon price

\begin{tabular}{lllllll} 
& \multicolumn{7}{c}{ (euro/ton) } \\
& 0 & 10 & 20 & 40 & 80 & 100 \\
\hline Timber revenue (euro/ha) & 5917 & 6954 & 7502 & 8005 & 8260 & 8327 \\
Carbon net revenue (euro/ha) & 0 & 440 & 954 & 2040 & 4213 & 5310 \\
$\quad$ - Carbon benefit & 0 & 1025 & 2180 & 4615 & 9500 & 11967 \\
$\quad$ - Carbon tax & 0 & 585 & 1226 & 2574 & 5287 & 6657 \\
Total revenue (euro/ha) & 5917 & 7394 & 8455 & 10045 & 12473 & 13637 \\
& & & & & & \\
Change in timber revenue (\%) & 17.5 & 26.8 & 35.3 & 39.6 & 40.7 \\
Change in total revenue (\%) & 25.0 & 42.9 & 69.8 & 110.8 & 130.5 \\
\hline
\end{tabular}

The carbon tax/subsidy programme is found to increase the income of forest owners considerably (Table4). As the net revenue from carbon sequestration only consists of the total revenue, the forest owner can, however, affect total revenue greatly by changing stand management. For example, with a carbon price of 10 euro/t the joint revenue would increase from 5917 euro/ha to 6286 euro/ha even without any change in silviculture. As applying optimal silviculture would increase the total revenue to 7394 euro/ha, the additional benefit from modifying silviculture would be 1108 euro/ha. Silviculture that includes the joint revenue from both timber production and carbon sequestration differs from timber-based silviculture. Both timber revenue and total revenue increase.

\section{Impact of forest size}

In this paragraph, we examine the effect of forest size on optimal rotation periods. As reported in Table 5, we consider three possible sizes of forest (i.e., we set $\mathrm{A}=6,12$ and $24 \mathrm{ha}$, respectively). The main conclusion from Table 5 is that the greater the size of forest, the shorter the optimal rotation period. One possible explanation is that when the size of the forest increases, the optimal rotation is shortened because the increase in gain due to the size is compensated by a lower harvest age in order to maintain a certain level of wealth. Another explanation is related to the risk aversion of the forest owner. As the size of forest increases, then the loss in the case of fire is also greater. As a result, risk aversion induces the forest owner to shorten the optimal rotation duration.

\section{Impact of fire risk}

Since global warming results in an increase in the frequency of extreme climatic events, it is interesting to analyze how optimal forest owner decisions are modified by changes in the risk of fire. In Table 6, we report the optimal rotation duration for several values of the fire risk arrival rate, $\lambda$. As expected, increasing the risk of fire reduces the rotation age. With a low fire probability, it is optimal to accumulate carbon in trees and in forest products with a long lifespan. With a high risk 
Table 5: Optimal rotation length, timber volume, and revenues as a function of the forest size Forest size

\begin{tabular}{|c|c|c|c|}
\hline & 6 & 12 & 24 \\
\hline Optimal rotation length (years) & 46 & 42 & 40 \\
\hline Timber volume $\left(m^{3} / h a\right)$ & 369 & 342 & 324 \\
\hline Carbon storage $($ ton $/ \mathrm{ha})$ & 111 & 103 & 97 \\
\hline Timber revenue (euro/ha) & 7649 & 6954 & 6484 \\
\hline Carbon net revenue $^{a}($ euro/ha) & 487 & 440 & 408 \\
\hline Total revenue $($ euro/ha) & 8136 & 7394 & 6892 \\
\hline Change in timber revenue (\%) & & -9.1 & -15.2 \\
\hline Change in total revenue $(\%)$ & & -9.1 & -15.3 \\
\hline
\end{tabular}

of fire, it is optimal to reduce the optimal harvest age and to store the carbon in forest products.

Table 6: Optimal rotation length, timber volume, and revenues as a function of risk

\begin{tabular}{lllllll}
\hline & \multicolumn{7}{c}{ Risk $\lambda$} \\
& $0.17 \%$ & $0.34 \%$ & $0.68 \%$ & $1.26 \%$ & $1.4 \%$ & $1.7 \%$ \\
\hline Optimal rotation length (years) & 42 & 41 & 40 & 39 & 39 & 38 \\
Timber volume $\left(\mathrm{m}^{3} / \mathrm{ha}\right)$ & 342 & 333 & 324 & 315 & 315 & 304 \\
Carbon storage $($ ton $/ \mathrm{ha})$ & 103 & 100 & 97 & 94 & 94 & 91 \\
& & & & & & \\
Timber revenue & 6954 & 6731 & 6484 & 6213 & 6213 & 5917 \\
Carbon net revenue ${ }^{a}($ euro/ha) & 440 & 425 & 408 & 390 & 390 & 369 \\
Total revenue (euro/ha) & 7394 & 7156 & 6892 & 6603 & 6603 & 6286 \\
& & & & & & \\
Change in timber revenue (\%) & & -3.2 & -6.8 & -10.6 & -10.6 & -14.9 \\
Change in total revenue (\%) & & -3.2 & -6.8 & -10.7 & -10.7 & -15.0 \\
\hline${ }^{a}$ with a carbon price of 10 euro/ton. & & & & & &
\end{tabular}

More specifically, the forest owner reduces the final timber stock exposed to fire risk as the fire risk increases. The rotation duration for maritime pine falls gradually from 42 years with a $0.17 \%$ fire risk to about 38 years with a $1.7 \%$ fire risk, which corresponds to the optimal rotation age obtained in the benchmark case, that is without any carbon price.

\section{Impact of risk preferences}

In order to evaluate the impact of risk preferences on optimal rotation age, the stochastic dynamic recursive equation was solved for various levels of the Arrow-Pratt constant relative risk-aversion coefficient (CRRA), $\beta$. We considered three levels of the CRRA coefficient: almost risk neutrality: $\beta=0.0001 ;$ moderate risk aversion: $\beta=0.5$; and extreme risk aversion: $\beta=1.5$.

As can be seen in Table 7, the optimal rotation age decreases as risk aversion increases. In the case of quasi risk neutrality $(\beta=0.0001)$, the forest owner does not use saving to smooth 
consumption; at each period during stand growth, consumption only depends upon carbon benefits. On harvesting, it depends on timber benefits. Intuitively, when risk aversion increases, the forest owner tries to avoid exposing its assets to risk. This can be achieved though earlier harvesting, which means a lower value being attributed to the forest stand. The forest owner can stabilize his consumption, first by having a high level of savings, and second by having a lower final timber stock exposed to fire risk. This second mechanism is made possible by harvesting sooner. In other words, higher saving together with a lower harvesting age provide better insurance against the variation in consumption due to catastrophic events. The higher the parameter of risk aversion, the higher the savings and the lower the cutting age. This can be explained intuitively. A risk averse forest owner wants to secure income. This can be achieved by having a higher level of wealth (with a certain return) and a lower timber level (asset with a high risk of loss).

Table 7: Optimal rotation length, timber volume, and revenues as a function of risk preferences

\begin{tabular}{llll}
\hline & \multicolumn{3}{l}{ Risk preferences $\beta$} \\
& $\begin{array}{l}\text { Risk neutral } \\
\text { Risk averse } \\
(0.0001)\end{array}$ & $\begin{array}{l}\text { Extreme risk averse } \\
(1.5)\end{array}$ \\
\hline Optimal rotation length (years) & 45 & 42 & 41 \\
Timber volume $\left(\mathrm{m}^{3} / \mathrm{ha}\right)$ & 363 & 342 & 324 \\
Carbon storage $($ ton $/ \mathrm{ha})$ & 109 & 103 & 97 \\
& & & \\
Timber revenue & 7502 & 6954 & 6731 \\
Carbon net revenue ${ }^{a}($ euro/ha) & 477 & 440 & 425 \\
Total revenue $($ euro/ha) & 7979 & 7394 & 7156 \\
& & & \\
Change in timber revenue (\%) & & -7.3 & -10.3 \\
Change in total revenue (\%) & & -7.3 & -10.3 \\
\hline${ }_{\text {with a carbon price of 10 euro/ton. }}$ & &
\end{tabular}

Implications of this result in terms of carbon sequestration are the following. As the cutting age decreases, less carbon will be sequestered in the stand. In spite of the positive carbon price, a risk-averse forest owner facing fire risks prefers to reduce the optimal rotation time. Hence risk preferences have important impacts on the effect of carbon policy. This factor needs to be integrated in the analysis in order to estimate the real effects of such policies on optimal forest management. It follows that forest owners' risk preferences should be viewed as important features of any framework aiming to analyze private forest owner decisions facing fire risk.

\subsubsection{Carbon price and fire risk increase mitigation}

Most carbon price scenarios predict a significant price increase over the next decades (Capoor and Ambrosi [45], Chladná [46]). Upwardly trending carbon prices will strengthen the rationale 
for storing carbon in trees. As shown previously, this will result in delaying the optimal date of harvesting.

Global warming due to climate change is expected to increase the frequency of extreme events such as fires (Stollery [11]). There has been a lot of research aimed at establishing the relationship between climate change and increased forest fires. There is now a broad consensus that fire risks are expected to increase over time as the climate warms. Increased fire risk will lessen the rationale for storing carbon in trees. As shown previously, this will result in shortening the optimal rotation.

The joint impact of fire risk and carbon price increase is a priori ambiguous since a forest owner will react to an increase in fire risk by reducing rotation duration. On the contrary, if carbon prices increase, then it is optimal to extend the rotation length. Increasing carbon prices has an opposite effect to the impact of an increase in fire risks, and without specific knowledge of the relative strengths of these effects, one cannot predict which of them will dominate. This is the question we will now investigate.

In what follows, we identify a frontier in the carbon price $\times$ fire risk space such that all points along this frontier result in the same optimal rotation age. More specifically, Figure 6 represents the carbon price/risk frontier maintaining the optimal rotation age at $\bar{t}^{*}=42$. Region I corresponds to couples (carbon price $\times$ fire risk) in which that the optimal rotation age is less than 42 years. On the contrary, for couples located in region II, the optimal rotation period is greater than 42 years.

In Figure 6 we have represented the (carbon price $\times$ fire risk) frontier for three levels of forest owner risk aversion. The plain line corresponds to the frontier in the benchmark case where the forest owner is supposed moderately risk averse, $\beta=0.5$. As expected, the frontier is increasing: an increase in fire risk must be compensated by an increase in carbon price in order to keep the rotation duration the same. The relationship between the risk of fire and the carbon price is almost linear along the frontier.

Finally, we analyze how the risk preferences of the forest owner modify the location of the (carbon price $\times$ fire risk) frontier. As can be seen in Figure 6 , for a given level of risk, the higher forest owner risk aversion, the higher the carbon price must be to maintain the rotation length at 42 years. For instance, for a risk of fire equal to $1 \%$, the carbon price inducing a 42 year rotation is 10.6, 13.8 and 16.6 euro/ton respectively in the case of a risk neutral, risk averse and extremely risk averse forest owner. The economic intuition of this result is straightforward. For a given level of fire risk, increasing the forest owner's risk aversion implies a reduction in the optimal rotation age. To maintain the optimal rotation length at 42 years for a very risk-averse forest owner, one must make the non-harvesting strategy very profitable. This is only possible with a very high carbon 
price which implies large benefits from keeping old tree generations. This result suggests that the rotation length appears to be very sensitive to the level of risk aversion. Any model aiming to provide policy implications must investigate the risk aversion of forest owners carefully.

Figure 6: Carbon price/risk frontier

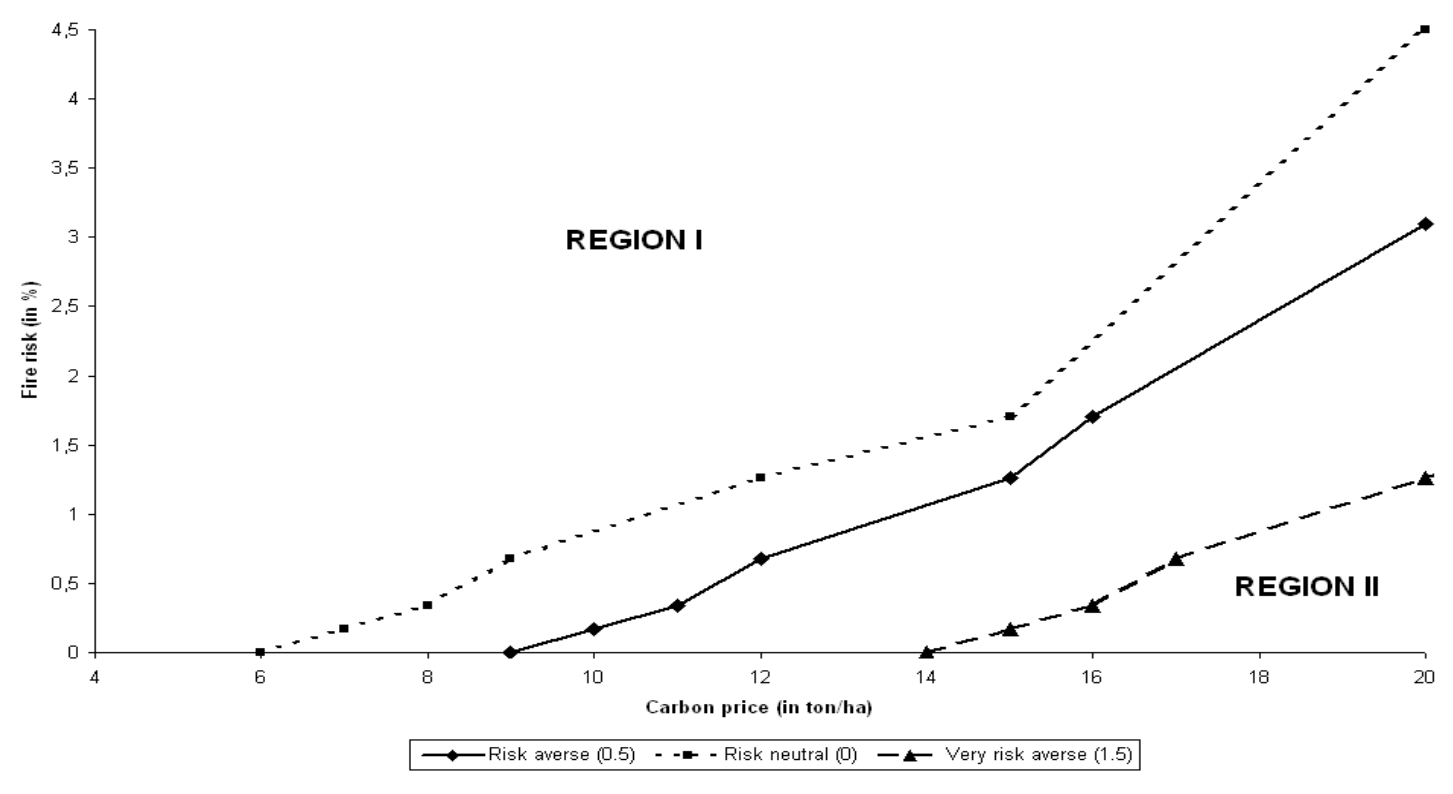

\subsection{Forest management and policy implications}

Efficient management of forests requires information on the magnitude of the global warming that has occurred or is likely to occur in the future, and estimates of the impact of global warming on factors including fire frequency and tree growth rates. At present, there is considerable uncertainty about the magnitude of climate change and its impact on forest management. One of the reasons for this uncertainty is that there is natural variability in climate, fire frequency and tree growth rates. The profitability of forest product increases when the benefit of sequestration of atmospheric carbon in forest biomass is taken into consideration. Benefits will have several important forest management implications. It will be optimal to increase rotation ages. An important issue is the relation to other environmental benefits from forestry like recreation and biodiversity conservation. Prolonging the rotation time increases these two benefits in most cases.

With a carbon fee, the economic value of forests will increase dramatically because of their potential as a carbon sink. Today there is no market to stimulate investments in this good. One important challenge will be to introduce policy means that make it possible to reach an optimal investment level regarding forests as carbon sinks. For private forests, one can in principle use 
regulation by law or economic policy means, or combinations of these. It would, however, be very difficult in most countries to make forest owners willing to increase forest biomass without economic compensation of some sort i.e. subsidies or tax incentives. Subsidies for carbon capture in forest biomass have to be followed by corresponding taxes on the release of carbon from the end-use of the forest biomass.

The numerical simulations provided here have some important implications for the ability of forests to act as carbon sinks. The countries ratifying the Kyoto agreement have obtained the right to use forests as absorbers of carbon to offset their need to reduce fossil fuel emissions. However, our findings indicate that if the climate warms, then fire risk will rise, reducing the carbon-absorbing ability of forests. The use of existing forests as carbon sinks may be a temporary option compared to increasing forest area or switching from forests with faster-growing species. Forest carbon sinks need to be preserved by preventive action to mitigate the effects of natural disturbances. Therefore, to keep forests' carbon absorption, some mitigation activities need to be implemented jointly with forest management activities. Policy measures can induce fire protection strategies to reduce fire risk. There is a greater incentive for forest owners to reduce risk or purchase insurance. In a carbon market the concern for mitigating risk will become even greater. Policies to help forest owners to manage and reduce their risk would therefore have a positive impact on the amount of carbon stored by forests.

In the same way, policy can affect the supply of sawtimber or pulpwood by changing the prices of timber products or limiting the fluctuations in such prices. In our model we assume that timber prices are constant over time, but it is clearly proved that these prices are volatile and uncertain. Some policy measures could reduce variations in timber prices. For example, imposing a minimum guaranteed threshold price in the sawtimber market to reduce the volatility of prices at some future time could impact on the supply of sawtimber by maintaining a high price for sawtimber. This policy could encourage longer rotations and more sawtimber production, increasing the carbon storage by forests and products. Another policy could affect pulpwood supply by taxing the revenue from such products. This measure could induce less pulpwood production and more sawtimber supply, encouraging carbon sequestration in growing trees and final products.

\section{Conclusion}

Public financial incentives for forest carbon sequestration might influence individual forest owners to postpone optimal rotation and protect their forest from natural damage. Catastrophic events 
can impact optimal forest management decisions because such events significantly alter the optimal production decision of a stand, and release some or all of the stored carbon back into the atmosphere. In this paper, we use an expected utility approach to analyze saving and forestry management jointly, in a stochastic intertemporal framework with a risk-averse forest owner. We have applied the stochastic dynamic programming framework to the management of a representative forest owner located in the south-west of France. Our empirical results show that risk preferences have a significant impact on optimal policies. The forest owner prefers shorter rotations as the risk increases to longer the rotations favorable to carbon sequestration. Risk preferences significantly confirm this behavior.

This research can be extended in many ways such as insurance or self-insurance and selfprotection activities, or public support funds. It is possible to introduce fire-risk coverage and prevention choices into the decision program of the forest owner. These decisions could impact optimal multiple-use forest management. Very often, in the case of catastrophic disasters in France, forest owners' financial losses are partially covered by compensation from public programs that guarantee a minimum value for damaged property. Introducing public program funds into the optimization program of the forest owner may significantly modify the optimal forest and consumption strategies. Another possible extension could be to introduce other amenity values and other financial assets into the decision making of the forest owner. The integration of multiple sources of revenues for the forest owner could alter the optimal forest and consumption-savings decision paths.

\section{References}

[1] IPCC, Guidelines for national greenhouse gas inventories, Tech. rep. (2006).

[2] M.-J. Schelhaas, G.-J. Nabuurs, A. Schuck, Natural disturbances in the european forests in the 19th and 20th centuries, Global Change Biology 9 (2003) 1620-1633.

[3] H. Hoen, The faustmann rotation in the presence of a positive $\mathrm{Co}_{2}$ price, in: M. Lindhal, E. F. Helles (Eds.), Proceedings of the Biennal Meeting of the Scandinavian Society of Forest Economics, Vol. 14, Gilleleje, 1994, pp. 52-58. 
[4] G. van Kooten, C. Binkley, G. Delcourt, Effect of carbon taxes and subsidies on optimal forest rotation age and supply of carbon services, American Journal of Agricultural Economics 77 (1995) 365-374.

[5] C. Romero, V. Ríos, L. Díaz-Balteiro, Optimal forest rotation age when carbon captured is considered: theory and applications, Journal of the Operational Research Society 49 (1998) $121-131$.

[6] L. Díaz-Balteiro, C. Romero, Forest management optimisation models when carbon captured is considered: a goal programming approach, Forest Ecology and Management 174 (2003) $447-457$.

[7] K. Akao, Faustmann problem when carbon sequestration service of a forest has value (2004).

[8] J. Gutrich, R. Howarth, Carbon sequestration and the optimal management of new hampshire timber stands, Ecological Economics 62 (3-4) (2007) 441-450.

[9] J. Pohjola, L. Valsta, Carbon credits and management of scots pine and norway spruce stands in finland, Forest Policy and Economics 9 (7) (2007) 789-798.

[10] G. Stainback, J. Alavalapati, Modeling catastrophic risk in economic analysis of forest carbon sequestration, Natural Resource Modeling 17 (3) (2004) 299-317.

[11] K. Stollery, Climate change and optimal rotation in a flammable forest, Natural Resource Modeling 18 (1) (2005) 91-112.

[12] R. Hartman, The harvesting decision when a standing forest has value, Economic Inquiry 14 (1976) 52-58.

[13] P. Samuelson, Economics of forestry in an evolving society, Economic Inquiry 14 (1976) 466492.

[14] W. Strang, On the optimal forest harvesting decision, Economic Inquiry 21 (1983) 576-583. 
[15] P. Johansson, K. Löfgren, The economics of forestry and natural resources, Basil Blackwell, Oxford, UK, 1985.

[16] M. Bowes, J. Krutilla, Multiple-use management of public forestlands, in: A. Kneese, E. J.L. Sweeney (Eds.), Handbook of Natural Resource and Energy Economics, Vol. 2, NorthHolland, Amsterdam, 1985.

[17] E. Koskela, M. Ollikainen, Forest taxation and rotation age under private amenity valuation: New results, Journal of Environmental Economics and Management 42 (2001) 374-384.

[18] J. Englin, P. Boxall, G. Hauer, An empirical examination of optimal rotations in a multiple-use forest in the presence of fire risk, Journal of Agricultural and Resource Economics 25 (1) (2000) $14-27$.

[19] G. Amacher, A. Malik, R. Haight, Not getting burned: The importance of fire prevention in forest management, Land Economics 81 (2) (2005) 284-302.

[20] J. Caulfield, A stochastic efficiency approach for determining the economic rotation of a forest stand, Forest Science 34 (1988) 441-457.

[21] R. Taylor, J. Fortson, Optimal plantation planting density and rotation age based on financial risk and return, Forest Science 37 (1991) 886-892.

[22] L. Valsta, A scenario approach to stochastic anticipatory optimization in stand management, Forest Science 38 (1992) 430-447.

[23] P. Gong, K.-G. Löfgren, Impact of risk aversion on optimal rotation age (2005).

[24] L. Alvarez, E. Koskela, Does risk aversion accelerate optimal forest rotation under uncertainty?, Journal of Forest Economics 12 (3) (2006) 171-184.

[25] W. Reed, Effects of the risk of fire on the optimal rotation of a forest, Journal of Environmental Economics and Management 11 (1984) 180-190. 
[26] O. Tahvonen, Bequests, credit rationing and in situ values in the faustmann-pressler-ohlin forestry model, Scandinavian Journal of Economics 100 (4) (1998) 781-800.

[27] O. Tahvonen, S. Salo, Optimal forest rotation with in situ preferences, Journal of Environmental Economics and Management 37 (1999) 106-128.

[28] S. Salo, O. Tahvonen, Renewable resources with endogenous age classes and allocation of land, American Journal of Agricultural Economics 86 (2) (2004) 513-530.

[29] O. Tahvonen, Optimal harvesting of forest age classes: a survey of some recent results, Mathematical Population Studies 11 (2004) 205-232.

[30] J. Uusivuori, J. Kuuluvainen, The harvesting decisions when a standing value forest with multiple age-classes has value, American Journal of Agricultural Economics 87 (1) (2005) 6176.

[31] S. Couture, A. Reynaud, Multi-stand forest management under a climatic risk : Do time and risk preferences matter ?, Environmental Modeling and Assessment 13 (2) (2008) 181-193.

[32] A. Dixit, R. Pindyck, Investment under uncertainty, Princeton University Press, New Jersey, 1994.

[33] L. Eeckhoudt, C. Gollier, Les risques financiers : Evaluation, Gestion, Partage, Ediscience international, 1992.

[34] B. Vannière, Tables de production pour les forêts françaises, E.N.G.R.E.F Press, Nancy, 1984.

[35] E. Koskela, M. Ollikainen, Timber supply, amenity values and biological risk, Journal of Forest Economics 5 (2) (1999) 285-304.

[36] I. Bateman, A. Lovett, Estimating and valuing the carbon sequestred in softwood and hardwood trees, timber products and forest soils in wales, Journal of Environmental Management 60 (2000) 301-323. 
[37] B. Guo, Recherche d'une sylviculture optimale à long terme pour les peuplements forestiers équiennes, Phd dissertation, ENGREF, Nancy, 1994.

[38] R. Stavins, The cost of carbon sequestration: a revealed-preference approach, The American Economic Review 89 (4) (1999) 994-1009.

[39] R. Newell, R. Stavins, Climate change and forest sinks: factors affecting the costs of carbon sequestration, Journal of Environmental Economics and Management 40 (2000) 211-235.

[40] R. Sedjo, R. Sampson, J. Wisniewski, Economics of Carbon Sequestration in Forestry, Lewis Publishers, Inc., 1997.

[41] K. Richards, C. Stokes, A review of forest carbon sequestration cost studies: a dozen years of research, Climatic Change 63 (1-2) (2004) 1-48.

[42] P. Vallet, Impact de différentes stratégies sylvicoles sur la fonction, 2005.

[43] R. Howitt, A. Reynaud, S. Msangi, K. Knapp, Estimating intertemporal preferences for natural resource allocation, American Journal of Agricultural Economics 87 (4) (2005) 969-983.

[44] K. Judd, Numerical Methods in Economics, M.I.T Press, Cambridge, 1998.

[45] K. Capoor, P. Ambrosi, States and Trends of the Carbon Market 2007, Washington: World Bank Institute., 2007.

[46] Z. Chladná, Determination of optimal rotation period under stochastic wood and carbon prices, Forest Policy and Economics 9 (2007) 1031-1045. 